\title{
CARTOGRAFIAS E CONFLITO TERRITORIAL NO QUILOMBO RIO DOS MACACOS
}

\section{CARTOGRAFIAS AND TERRITORIAL CONFLICT IN QUILOMBO RIO DOS MACACOS}

\section{Paula Regina de Oliveira Cordeiro}

paulareginacordeiro@gmail.com

Doutoranda em Geografia. Mestra em Geografia pela Universidade Federal da Bahia, pesquisadora do Grupo Costeiros - UFBA e da Nova Cartografia Social

- Núcleo de Estudos Agroecológicos - UFRB

ORCID: https://orcid.org/0000-0002-5832-3860

\section{RESUMO}

Este artigo tem por objetivo apresentar as relações de conflito no território do Quilombo Rio dos Macacos, comunidade que desde a década de 1950 está em conflito com a Marinha do Brasil. A partir da judicialização do conflito, em 2009, a cartografia é utilizada tanto pelos sujeitos que detêm o conhecimento especializado quanto pela comunidade, pelos sujeitos autóctones. As diferentes formas de representação do território quilombola são notadas a partir da finalidade com que o mapa é construído. Com a apropriação da cartografia, os quilombolas avançam nos debates acerca das propostas apresentadas pelos sujeitos hegemônicos do conflito, produzindo contrapropostas e imprimindo novas cartografias e contornos para o conflito territorial.

Palavras-chave: quilombo Rio dos Macacos; cartografias; conflito territorial.

\section{ABSTRACT}

This article aims to present the conflict relations in the territory of Quilombo Rio dos Macacos, the community that since the 1950s has been in conflict with the Brazilian Navy. From the judicial judicialization of the conflict, in 2009, cartography is used both by the subjects who hold the specialized knowledge and by the community, by the autochthonous subjects. The different forms of representation of the quilombola territory are noted from the purpose with which the map is constructed. With the appropriation of cartography, the quilombolas advance in the debates about the proposals presented by the hegemonic subjects of the conflict, producing counterproposals and printing new cartographies and outlines for the territorial conflict.

Keywords: Quilombo Rio dos Macacos; cartografias; territorial conflict.

\section{INTRODUÇÃO}

O mapa é uma representação de determinada(s) perspectiva(s) da realidade. Essa representação está estreitamente relacionada ao que está sendo mapeado, quem está mapeando, como e em que condições e 
contextos a cartografia está sendo realizada. É impossível representar a totalidade do território em uma cartografia, já que, a priori, todo o mapa apresenta certa deformação, posto que a informação não plana será transformada em uma representação plana. Essa deformação acontece na medida em que se escolhe uma projeção geográfica.

A projeção geográfica mais utilizada na elaboração dos mapas é de Mercator. Nessa projeção os meridianos e os paralelos são linhas retas que se cortam em ângulos retos. Essa projeção mantém a forma dos continentes, mas altera as proporções reais. Nela as regiões polares e o hemisfério norte acentuam-se, além disso, o continente europeu ganha a centralidade do mapa, evidenciando forte eurocentrismo.

A projeção de Peters, utilizada com menos frequência, surge como crítica à projeção de Mercator. A projeção de Peters deforma o formato dos continentes, porém mantém a área proporcional mais próxima do real. Ao contrário da projeção de Mercator, a projeção de Peters coloca o continente africano no centro do mapa.

O plano de fundo sobre a utilização das projeções cartográficas é a visão de mundo que orienta a elaboração dos mapas, responsável por mostrar determinados elementos e subtrair outros. Assim como as projeções cartográficas, as cartografias visam firmar através da legitimidade da técnica, quais os mundos, os territórios, as políticas e as populações são visíveis, ou seja, aceitas:

O imaginário cartográfico e as representações do território passaram assim a recortar o real para descrevê-lo, defini-lo e, simbolicamente, possuí-lo. As representações cartográficas passaram igualmente a subordinar-se aos imperativos territoriais dos sistemas políticos que as reclamavam e justificavam. O território plural e polissêmico, aberto ao aleatório e não controlável, foi sendo transformado em extensão quantificada, limitada e controlada pelo gesto cartográfico que serve de suporte à ação política. Mas, a despeito de ser correntemente apresentado como um enunciado constatativo do real, o mapa não deixa de ser um enunciado performático, que diz algo sobre o real e sobre este produz efeitos (ACSELRAD; COLI, 2008, p. 13).

É na disputa pela permanência no território e pelo direito de se fazerem visíveis nas cartografias que o Quilombo Rio dos Macacos cria estratégias de reexistência diante do conflito territorial com a Marinha do Brasil.

\section{CONFLITOS TERRITORIAIS NO QUILOMBO RIO DOS MACACOS}

O Quilombo Rio dos Macacos (Mapa 1) está localizado no município de Simões Filho e possui aproximadamente 70 famílias em seu território. Esse território é marcado pela herança de ex-escravizados e quilombolas 
que sobreviveram aos séculos de exploração na Baía de Todos os Santos. Sua territorialidade é delimitada principalmente pela pesca artesanal nos rios e na barragem do Rio dos Macacos (pós década de 1970) ${ }^{1}$, pela pesca artesanal na Baía de Aratu, pela agricultura, pelo extrativismo e por demais práticas tradicionais. A partir dessas vivências, os quilombolas constroem sua identidade e definem seu território:

A terra constitui a base geográfica fundamental da manutenção da comunidade e da coletividade. Nesse sentido, a territorialidade se apresenta como o espaço coletivo do grupo social para firmar sua ocupação, para manter o seu ambiente e ter definido o seu território (ANJOS, 2009, p. 8).

Mapa 1 - Localização do Quilombo Rio dos Macacos

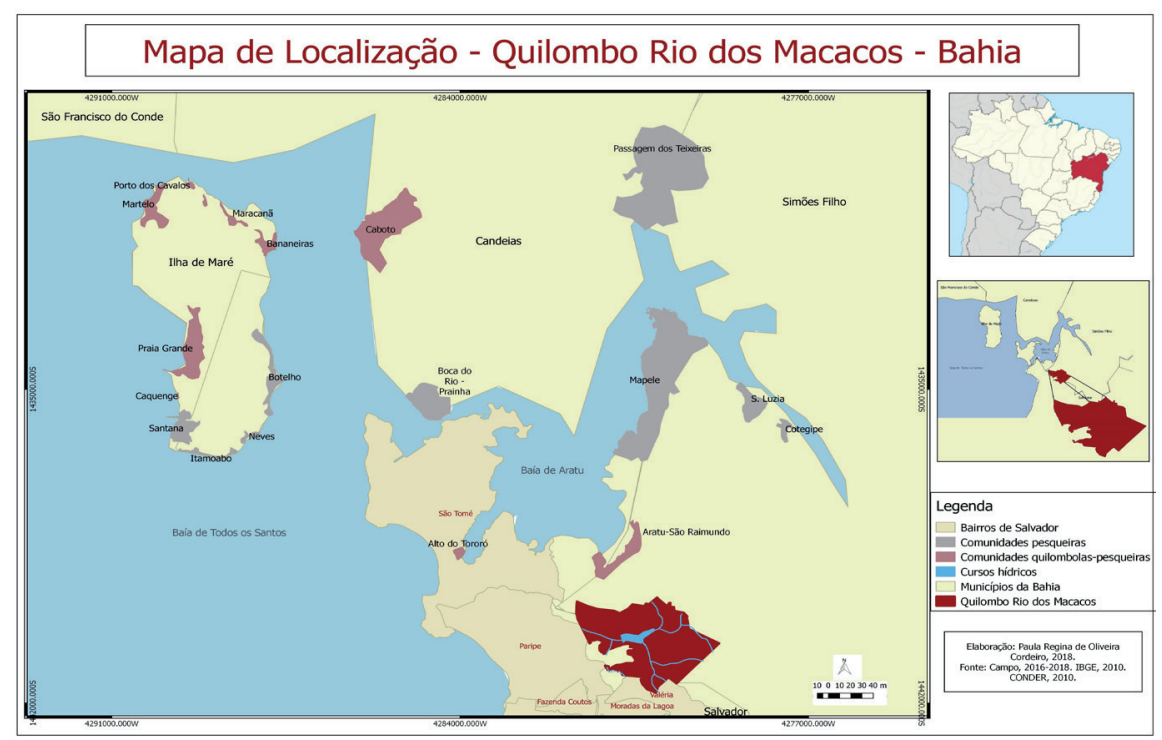

Fonte: CORDEIRO, 2018.

As atividades produtivas de Rio dos Macacos conformam não apenas o seu território, mas também a sua identidade, revelando uma articulação entre território e identidade. Sem território, não há identidade; e sem identidade, o território se esvazia de sentido. Na comunidade, a identidade pesqueira e a identidade quilombola se entrelaçam, sendo acionadas conjunta ou separadamente a partir das estratégias adotadas.

A partir da década de 1950, a Marinha do Brasil começa a ocupar a região e inicia um processo de instalação de fixos: edificações e equipamentos inerentes ao funcionamento da atividade militar. A ocupação mais efetiva foi na década de 1970, com o início do barramento do Rio dos Macacos e a construção das habitações para os fuzileiros navais, consolidando a Vila Naval da Barragem.

Obviamente, a instalação da Marinha no território fora marcada pela imposição de novos fluxos e estranhas dinâmicas. Dentre essas, destacam-se a expulsão de moradores através de ameaças, estupros 
de mulheres, do impedimento da construção ou reformas das casas, da negação da manutenção das culturas de subsistência e do acesso à infraestrutura básica como água e energia elétrica, além do ataque direto à religiosidade quilombola, consolidado no fechamento e destruição de terreiros de candomblé.

Com a construção da Vila Naval da Barragem, locais de memória foram destruídos:

Aqui onde hoje é a Vila Naval tinha terreiro de Candomblé. Tinha o terreiro de Gerson. Onde tem o centro comunitário da Marinha tinha a casa de seu Antonio Branco. Foi uma perda mesmo desgraçada. Eles chegaram aqui e acabaram com a nossa alegria. A gente ficou com medo (Dona Olinda).

A entrada da Marinha do Brasil coibiu e proibiu as práticas culturais da Comunidade, bem como conduziu o processo de expulsão dos quilombolas da região.

Segundo o Relatório Técnico de Identificação e Delimitação (RTID) elaborado pelo Instituo Nacional de Colonização e Reforma Agrária (INCRA), um caso específico pode servir para demonstrar esse processo. A Família Rabeca, que há cinco gerações ocupa o território, teve diversos membros expulsos, como é o caso de uma mulher e seus filhos que, após a morte do marido, "permaneceram no sítio até o momento em que a casa em que viviam caiu e eles se viram obrigados a deixar o lugar, pois, segundo declaram, não receberam autorização da Marinha para construir uma nova casa" (INCRA, 2012, p. 140).

Após a chegada da Marinha, a vida da comunidade foi se transformando em miséria e proibições, regadas de todos os tipos de violências, segundo Dona Albertina: "no processo de proibições até a comida para chegar aqui dentro a gente passava em sacos pequenos, para não ser vistos".

Apesar da existência, muitas comprovadas, desses e de diversos outros conflitos que envolvem as ações, práticas e condutas de violação de direitos humanos (segurança, moradia, trabalho etc.), o conflito atinge patamar jurídico em 2009.

Em outubro de 2009, foi ajuizada pela Marinha do Brasil uma ação reivindicatória requerendo a desocupação do território. Foi a primeira de quatro ações ajuizadas com o mesmo objetivo. Em novembro de 2010 foi proferida a primeira decisão interlocutória determinando a desocupação do local. Entretanto essa decisão foi suspensa posteriormente em razão das negociações em curso entre a comunidade, a Marinha do Brasil e outros órgãos dos governos federal e estadual.

No mês de setembro de 2011, após intensa mobilização comunitária, a Fundação Cultural Palmares certifica o Quilombo Rio dos Macacos como uma Comunidade Remanescente de Quilombo (CRQ) e em novembro do mesmo ano, o INCRA inicia a elaboração do RTID. O RTID foi apresentado à comunidade em agosto de 2012 e delimitou o território quilombola em 301 hectares (ha) (Mapa 2). 
Mapa 2 - Delimitação do território quilombola pelo INCRA
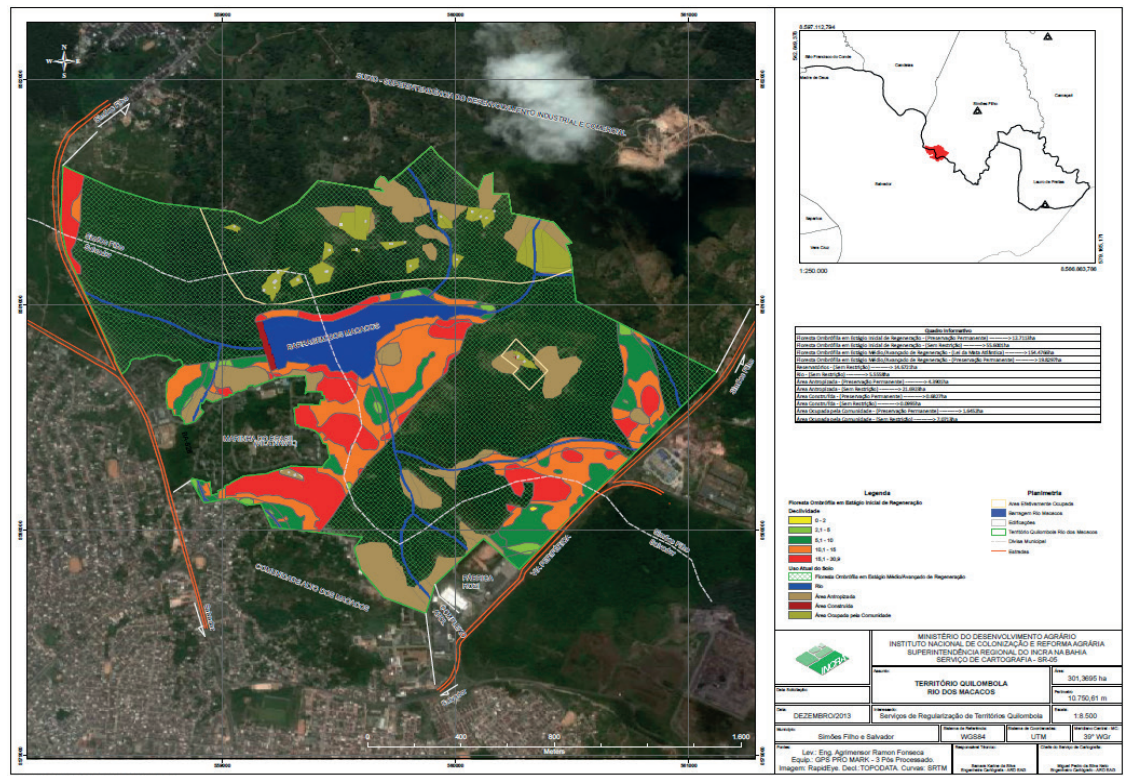

Fonte: INCRA, 2012

Apesar de ter elaborado o RTID, o INCRA não deu prosseguimento ao processo de regularização fundiária.

Com os impedimentos colocados à publicação do RTID tem-se início a Câmara de Conciliação do Ministério Público Federal (MPF), cuja execução estava sob a responsabilidade da então subprocuradorageral da República, Deborah Duprat, coordenadora da 6a Câmara de Coordenação e Revisão do MPF.

A partir da realização de audiências públicas, adiciona-se ao conflito territorial vigente até então, a disputa cartográfica:

A valorização política e analítica da dimensão espacial de fenômenos, processos, objetos e atores coloca os instrumentos de representação espacial cada vez mais no centro de disputas de poder. Esta valorização do espaço é que faz com que a cartografia cada vez mais se cruze com jogos e disputas, ou, ela própria se torne objeto de disputa (SANTOS, 2012, p. 1).

É necessário lembrar que a Câmera de Conciliação instalada foi fruto da insistência política dos quilombolas, que não aceitavam de forma alguma sua expulsão ou a "transferência da comunidade" para uma "área crua", como afirma seu Joselito, quilombola.

\section{DISPUTAS CARTOGRÁFICAS NO/DO QUILOMBO RIO DOS} MACACOS

O conflito do Quilombo Rio dos Macacos, desde o início se refere ao controle do território, dos elementos naturais, principalmente da barragem do Rio dos Macacos. 
A primeira proposta feita pelo Estado à comunidade foi de 7,5 hectares fora do território quilombola. Em dezembro de 2012, a Secretaria Geral da Presidência da República apresenta a "Proposta do Governo Federal para a Comunidade do Rio dos Macacos", na qual são ofertados 21 hectares para titulação da comunidade 3 . Obviamente, diante da inviabilidade produtiva e organizativa da comunidade, as duas primeiras propostas do Governo Federal foram prontamente recusadas pelo Quilombo, dando abertura então a novos processos de negociação.

Em outubro de 2013, o Governo Federal, através de uma nova audiência pública, fez a terceira proposta à comunidade, de 28,5 hectares. Essa proposta era a soma dos 7,5 ha e 21 ha oferecidos anteriormente e assim como as demais propostas, essa também não foi aceita. Sobre as propostas apresentadas Rose Meire afirma: "Não é justo que a gente seja expulso da nossa terra. É um absurdo o que a Marinha de Guerra do Brasil fez e faz com a gente".

Figura 1 - Propostas à Comunidade Quilombo Rio dos Macacos

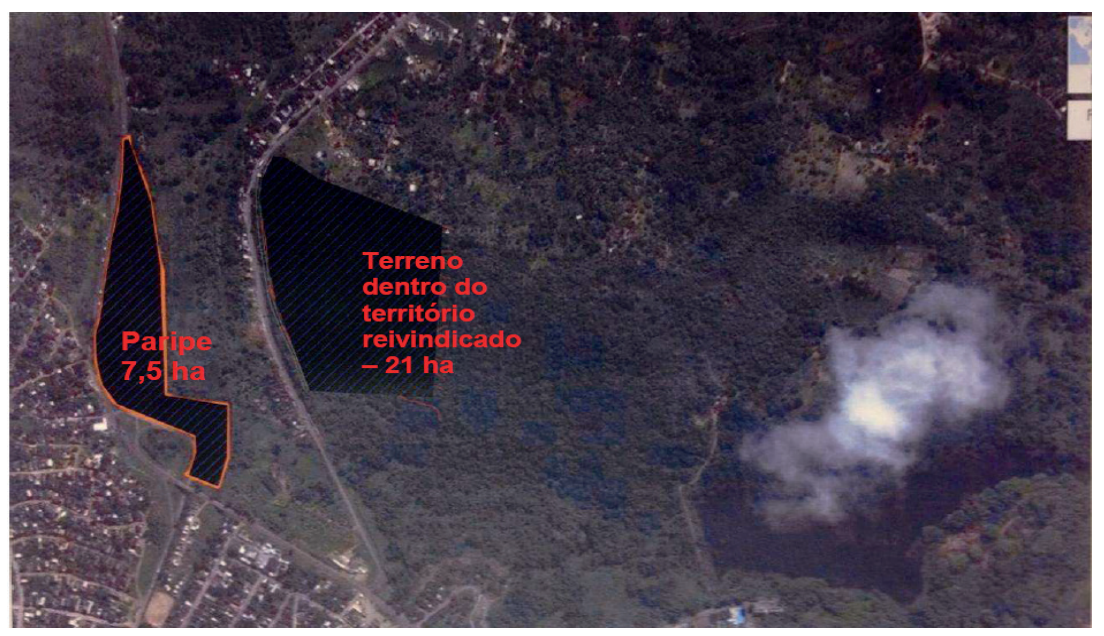

Fonte: Brasil, 2013.

Em março de 2014, o Governo Federal apresentou a quarta proposta para o "Ordenamento fundiário do território quilombola Rio dos Macacos”, oferecendo 86 hectares (Mapa 3). 
Mapa 3 - Proposta à Comunidade Quilombo Rio dos Macacos de 86 hectares

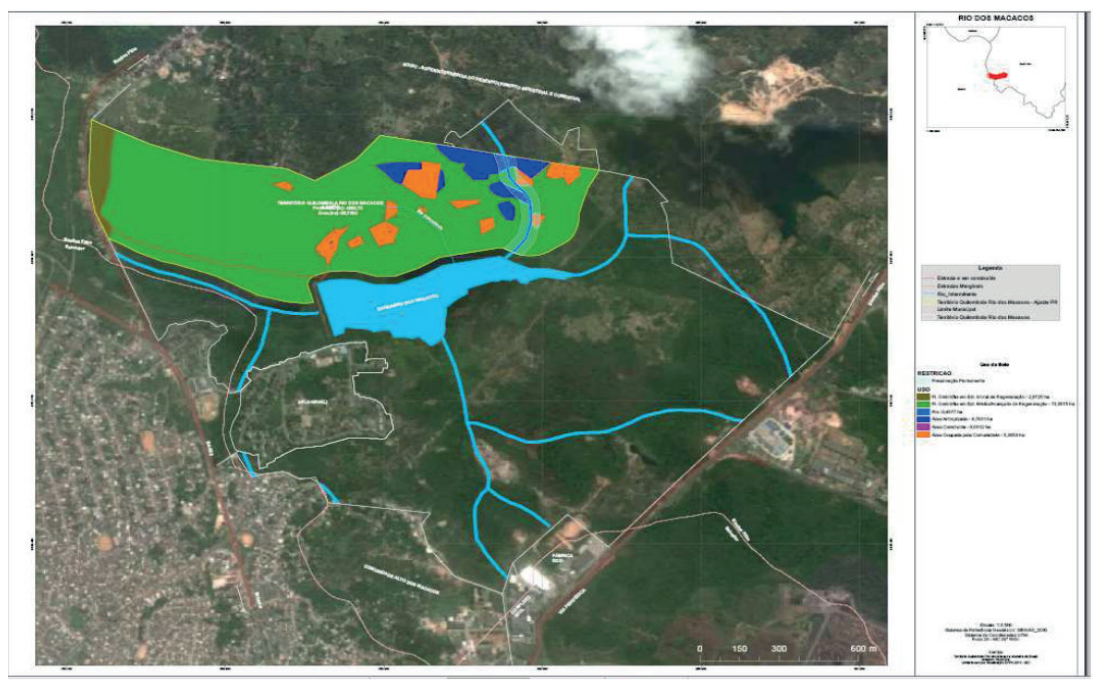

Fonte: Incra, 2014

A partir da quarta proposta, o Quilombo Rio dos Macacos resolve apresentar uma contraproposta. É então que a comunidade tem a necessidade de se apropriar dos elementos cartográficos da disputa territorial e tem-se início oficinas, conversas, diálogos cartográficos (Figura 2).

Figura 2 - Oficinas de Cartografia no Quilombo Rio dos Macacos

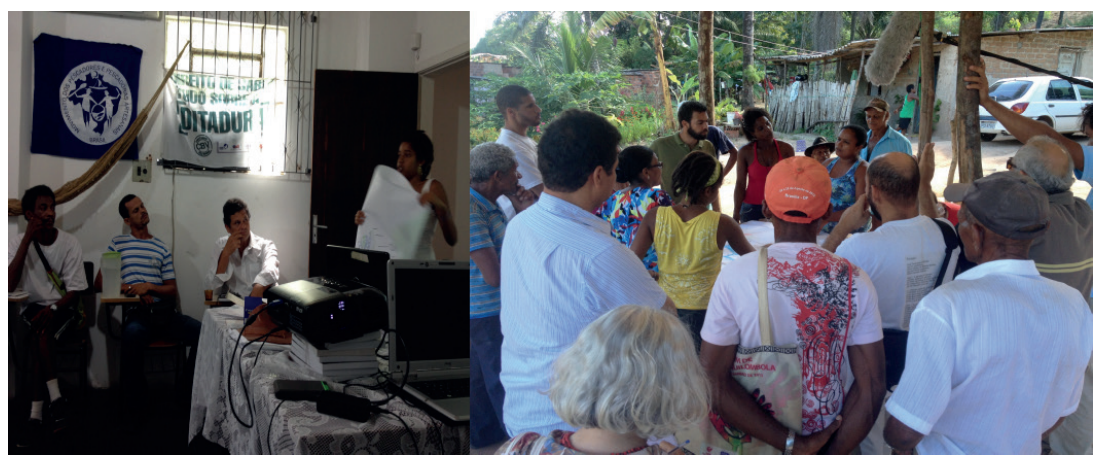

Fonte: Acervo Coletivo, 2014.

Em 6 de maio de 2014 em audiência no Ministério Público Federal, a Associação de Moradores do Quilombo Rio dos Macacos apresenta a primeira contraproposta (Mapa 4). A contraproposta apresentada pelos quilombolas representa a negação da proposta de 86 hectares apresentada anteriormente. $\mathrm{O}$ elemento principal de divergência com esta proposta é a negação dos cursos hídricos já que, o único curso hídrico que ficaria no interior da comunidade seria intermitente e insuficiente para manutenção dos hábitos e do modo de vida de uma comunidade pesqueira e quilombola. Outro elemento negativo foi o impedimento do acesso à barragem para uso da comunidade. 
Mapa 4 - Contraproposta do Quilombo Rio dos Macacos
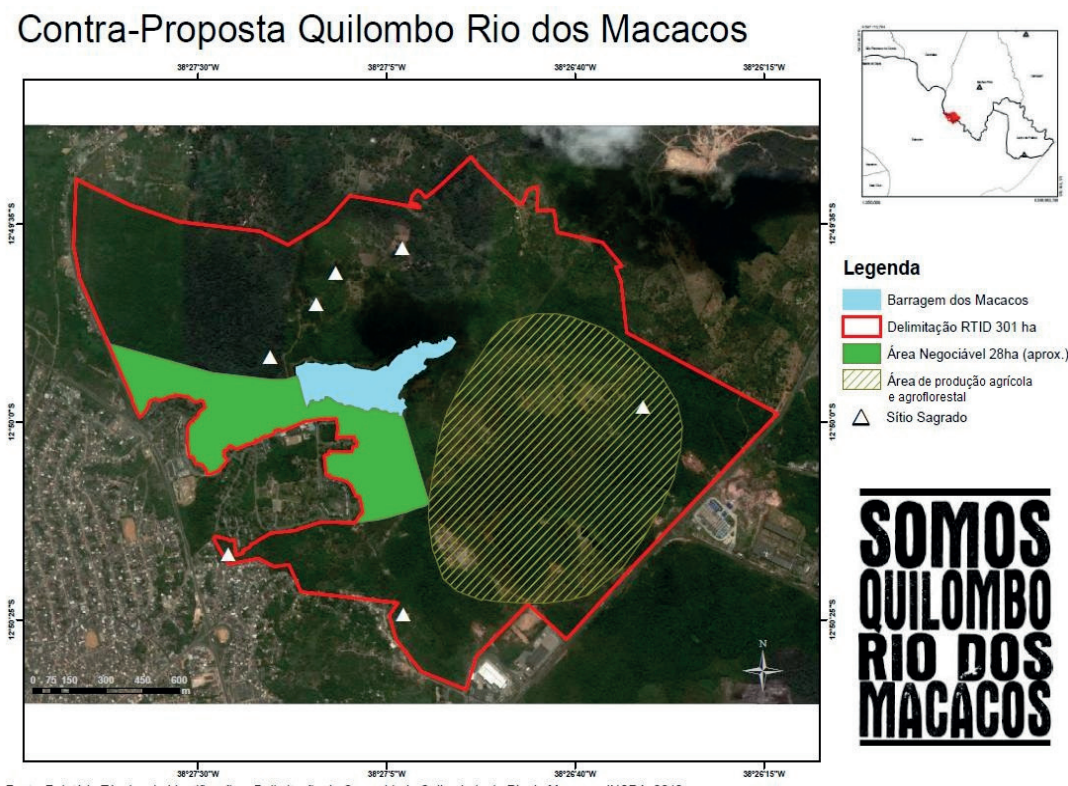

Cartografia: CORDEIRO, Paula, 2014.

A contraproposta apresentada pela Comunidade tinha como princípio o compartilhamento da barragem do Rio dos Macacos, a preservação dos sítios sagrados (Gameleiras e locais de oferendas) e a consolidação de área de produção agrícola e agroflorestal. A área negociada pela comunidade é a de 28 hectares para Marinha do Brasil - dos 301 hectares -, área que serviria de amortecimento entre a Vila Militar e o Quilombo. Tenta-se, com a contraproposta, diminuir as violências. Disso restariam para o uso, ocupação e desenvolvimento dos quilombolas 273 hectares.

Além da contraproposta, foi elaborado o primeiro mapa de perdas territoriais do Quilombo. Foi quando os quilombolas começaram a afirmar que os 301 hectares já representava uma perda territorial, pois o território ancestral, original é de mais de 900 hectares. Esse mapa foi também foi apresentado na audiência pública em maio de 2014 (Mapa 5). 
Mapa 5- Perdas territoriais da Comunidade Quilombo Rio dos Macacos

\section{Mapa de Perdas Comunidade Quilombo Rio dos Macacos}

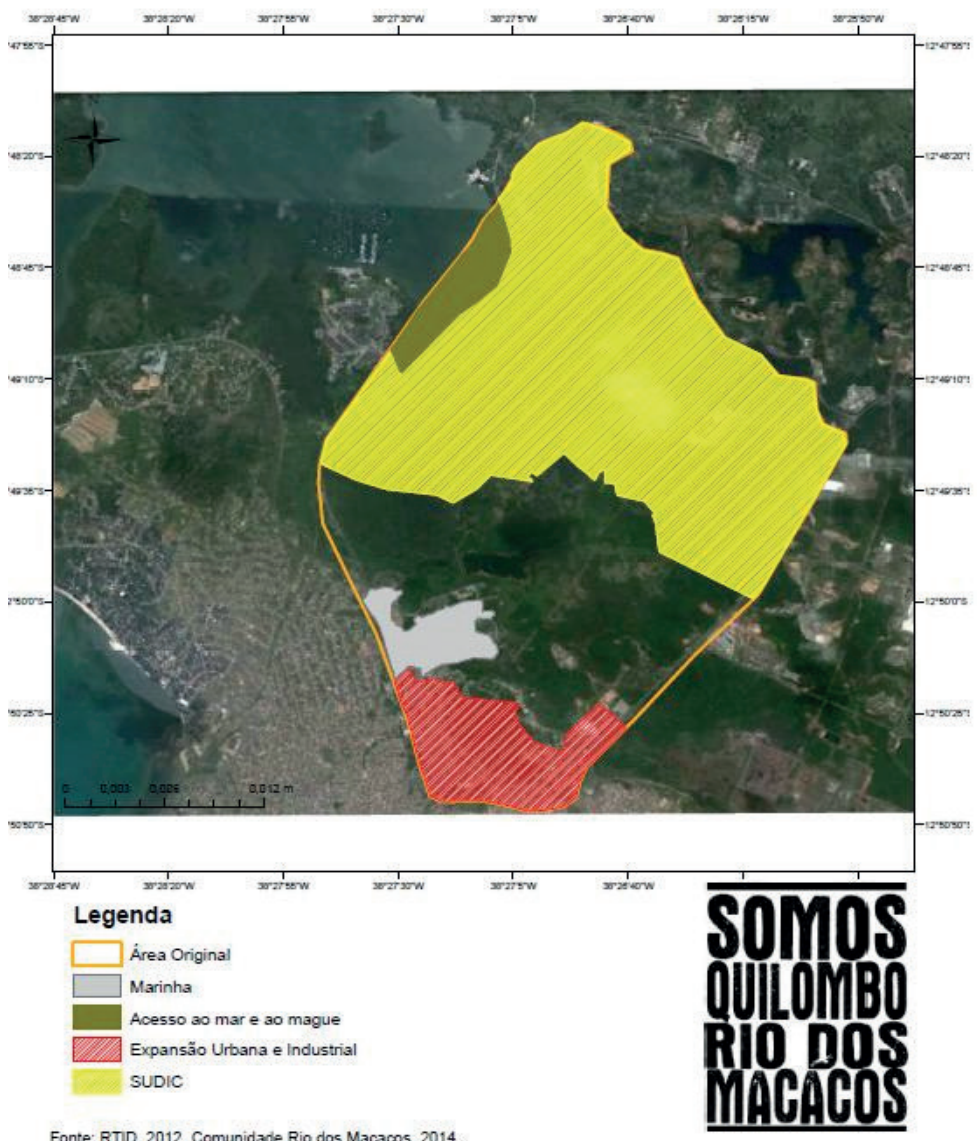

Cartografia: CORDEIRO, 2014.

Em 6 de maio de 2014, após apresentação da contraproposta por Rose Meire e Dona Olinda foi notado o desconforto gerado nos órgãos públicos e na Marinha do Brasil. Nesse momento, o quilombo Rio dos Macacos utiliza a própria leitura social do território e a confronta com as leituras oficiais e a dos atores hegemônicos, disputando o território, mas também disputando a imagem, a forma e o conteúdo deste através da cartografia, fazendo, portanto, política.

Somados à constatação de que na proposta de 86 hectares não haveria nenhum rio permanente no território, Seu Wilian lembrou que mesmo com o andar das negociações, eles (os quilombolas) estavam sofrendo ameaça de remoção por conta do processo judicial de desapropriação ainda em curso. Nesse sentido, a então subprocuradora-geral da República, Deborah Duprat, afirmou que a continuação do processo judicial inviabiliza as negociações, pois os quilombolas se sentem pressionados para negociar. Após essa declaração, há a suspensão da audiência pública. 
Após a suspensão da audiência, o governo Federal apresentou ${ }^{4} \mathrm{o}$ que seria a quinta proposta à comunidade. $\mathrm{O}$ diferencial da proposta apresentada anteriormente é que além dos 86 hectares ao norte da barragem, haveria a inclusão de seis hectares ao sul da Vila Naval, com mais 12 hectares do terreno da Superintendência de Desenvolvimento Industrial e Comercial (SUDIC), ao norte da barragem, totalizando uma área de 104 hectares. A utilização da barragem do Rio dos Macacos pelos quilombolas foi colocada como sendo inegociável.

A comunidade novamente rejeitou a proposta, já que essa mantém os aspectos básicos da anterior: a negação dos recursos hídricos e do uso compartilhado da barragem; assim como sugere a fragmentação do território, propondo dois "núcleos quilombolas".

De acordo com o MPF/BA ${ }^{5}$, o advogado Bruno Cardoso, da Advocacia-Geral da União, "comprometeu-se a interpor recursos pedindo a suspensão do processo judicial travado entre a Marinha e a comunidade" e também contra a liminar que impede a reforma das casas da comunidade.

Porém, após audiência pública, a nota oficial do Governo Federal, através do Ministro Gilberto Carvalho, afirma que: "não havendo o acordo, não há muito o que fazer, porque a Marinha não pode retirar a ação que move na Justiça, para reintegrar aquela área" (BRASIL, 2014). Ainda segundo o ministro, “o Governo Federal ainda está aberto a retomar as negociações, desde que os quilombolas revejam sua posição e aceitem a delimitação apresentada na reunião, uma vez que ela contempla os interesses dos diversos órgãos federais envolvidos na questão" (BRASIL, 2014).

Ao fim da audiência, o MPF exige que o RTID seja publicado pelo INCRA no prazo de 30 dias. Após recorrer aos prazos estabelecidos em agosto de 2014 o INCRA publica o RTID. Porém, ao invés dos 301 ha identificados e delimitados, há a publicação de 104 ha (mapa 6), conforme a última proposta "apresentada" pela Presidência da República. 
Mapa 6 - Proposta de 104 hectares - Marco de regularização atual do Quilombo Rio dos Macacos

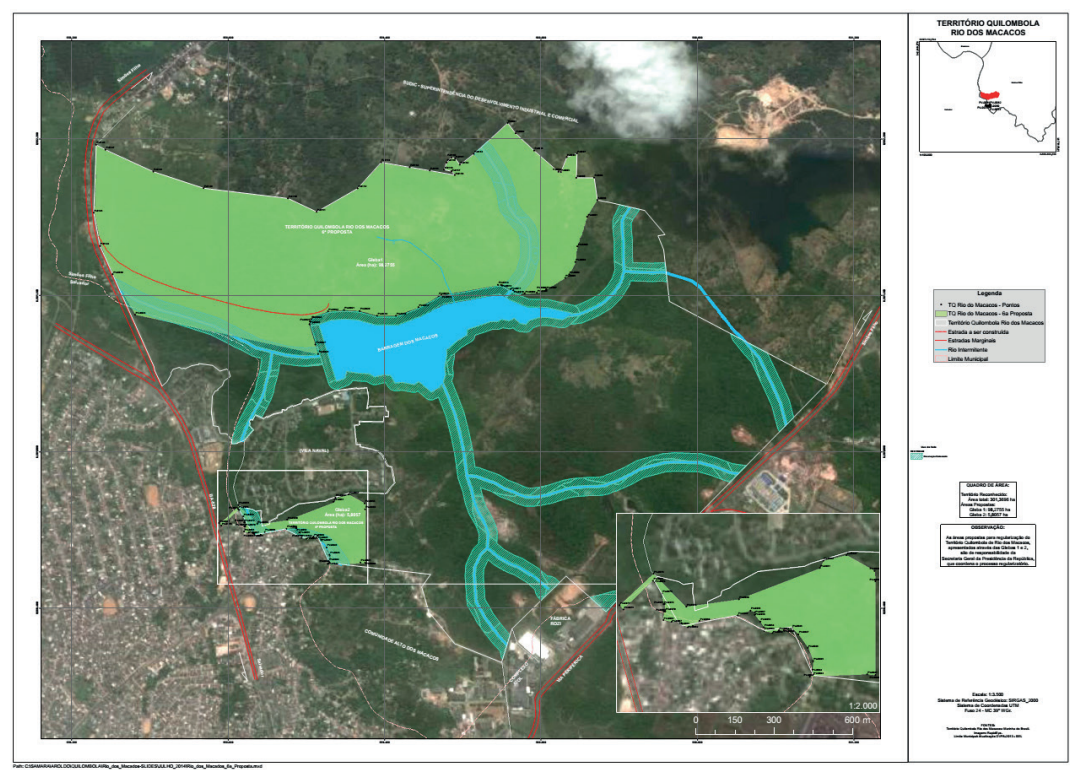

Fonte: Brasil, 2014

Os 104 ha fragmentam o território em duas glebas: a primeira, na área norte-noroeste do território, possui 98,2755 ha; a segunda possui 5,8057 ha e está localizada a sudoeste. A princípio essa proposta ignora e desrespeita a decisão quilombola contrária à fragmentação territorial.

Os quilombolas afirmam a inviabilidade de residência e do desenvolvimento familiar em 104 ha; esse valor contraria, inclusive, o tamanho do módulo fiscal da região. Segundo documento publicado pela Empresa Brasileira de Pesquisa Agropecuária (EMBRAPA), que regulamenta a variação geográfica do tamanho dos módulos fiscais no Brasil, em Simões Filho o módulo é de 7 ha.

Não se trata apenas da questão quantitativa do território, mas também das questões culturais, da existência de um território continuo no Quilombo - "Um Quilombo só" é condição necessária para a sua reprodução econômica que depende dos elementos naturais existentes.

O acesso e uso compartilhado da barragem do Rio dos Macacos é também condição necessária para a manutenção da vida quilombola. Pois sem água, a comunidade será impossibilitada de realizar suas atividades produtivas ligadas à pesca e a agricultura. Sendo assim, está destinada a caminhar em direção à favelização, significando a destruição do território conhecido até então.

Em novembro de 2015 foi publicada a portaria $n^{\circ} 623$ de reconhecimento do território quilombola.

Atualmente, o Quilombo Rio dos Macacos possui acesso à energia, a projetos educacionais como o Todos Pela Alfabetização (TOPA). Por outro lado, o acesso independente à entrada da Vila Naval da Barragem 
ainda não foi construído e os quilombolas continuam sendo ameaçados e sofrendo violências.

Apesar disso, o Quilombo Rio dos Macacos deu prosseguimento ao mapeamento, já que a disputa pelo território não acabou. Ganhando visibilidade, a questão da água. É sobre isso que me debruçarei a partir de agora.

\section{CARTOGRAFIA E TERRITORIALIDADE QUILOMBOLA}

As cartografias elaboradas pelos sujeitos hegemônicos do conflito territorial no Quilombo Rio dos Macacos se mostraram insuficientes para retratar a territorialidade quilombola. Esse conhecimento cartográfico tende a representar os territórios a partir de lógica exógena: "O conhecimento exerceria assim - e fortemente - seu papel de recurso, participando do clássico processo pelo qual, no sistema capitalista, os detentores de recursos competem vantajosamente com os que deles não dispõem" (SANTOS, 2006, p. 243).

Com a possibilidade de mapear, o Quilombo Rio dos Macacos encontra na cartografia um "instrumento de identidade e articulação, e também de disputa nas leituras e representações da realidade que servem de base para tomadas de decisão e ações" (SANTOS, 2012, p. 4). Em colaboração, aprendemos novas formas de pensar para agir, o pensar no espaço, e o pensar com o espaço.

Juntos criamos um plano de trabalho, o qual envolveu oficinas de cartografia e levantamento de GPS dos 301 hectares reivindicados pela comunidade. O processo durou 1 ano. Os produtos cartográficos foram inúmeros, um dos considerados mais significativos pela comunidade foi o mapa dos Mananciais Hídricos (Mapa 7), no qual a comunidade demonstra quais os cursos hídricos existem e os seus respectivos nomes, todos os cursos hídricos possuem relação com a barragem do Rio dos Macacos. Além dos rios, foram mapeadas as fontes. 


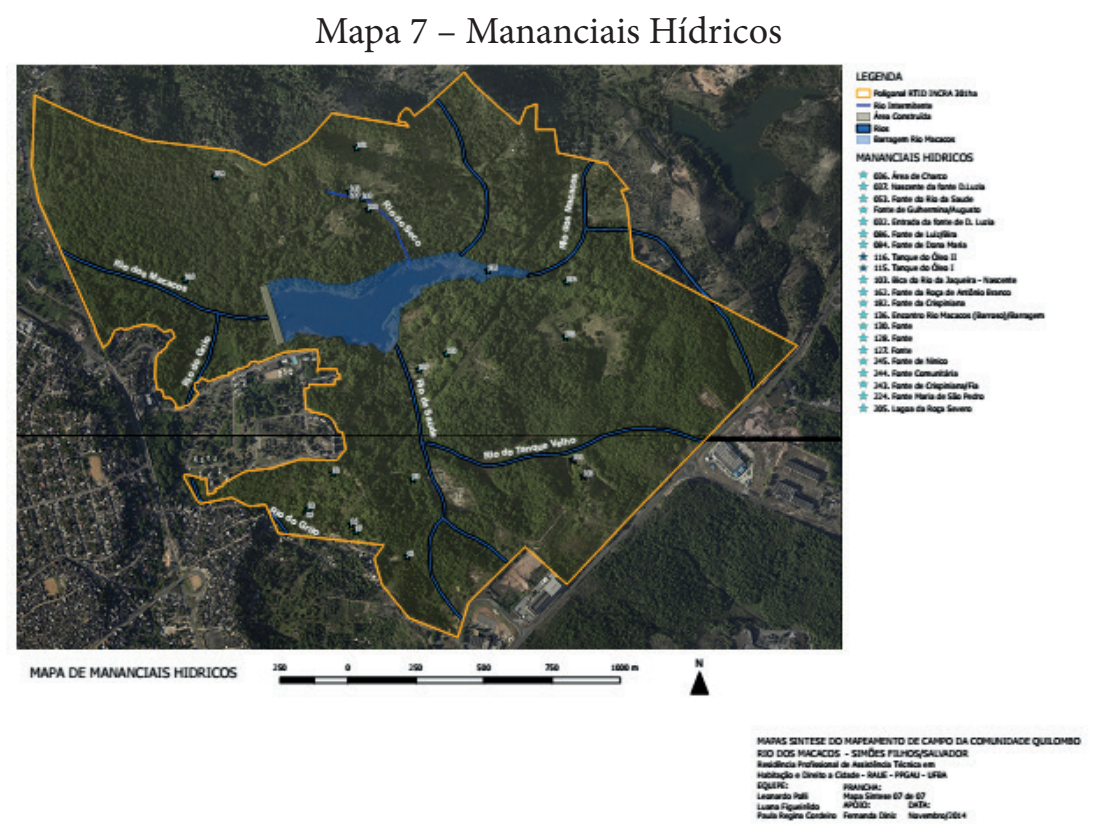

Fonte: CORDEIRO, 2014

Outro mapa importante foi o que representa a produção do Quilombo Rio dos Macacos (Mapa 8). Esta é fonte de orgulho para os quilombolas, pois é a partir dessas práticas espaciais que a territorialidade quilombola foi se constituindo. A produção quilombola consiste na agricultura, no extrativismo nas matas e na pesca nos rios e, com destaque em Rio dos Macacos.

Mapa 8 - Atividade Produtiva

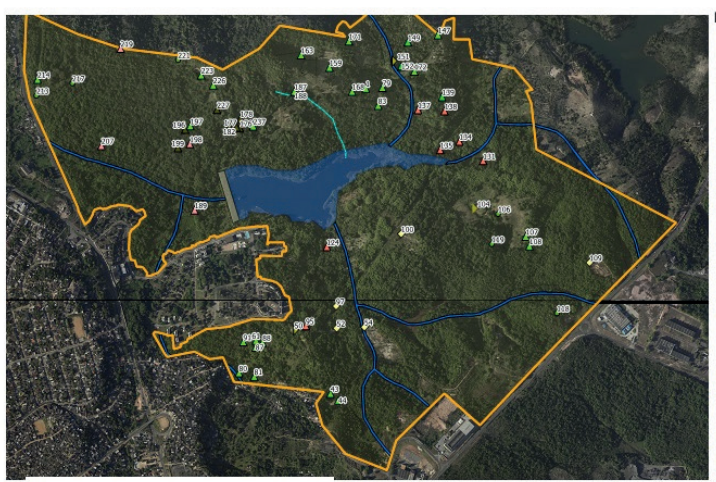

anc

043. Roca de Dedilison
061. Entradata casa e roca de leninha

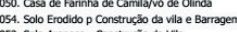

052. Solo Arenoso - Construçón de Vila

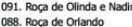

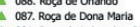

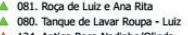

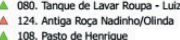

108. Pasto de Henrique
107. Roga de Henrique

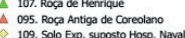

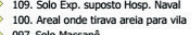

104. Case Henrique (Antiga cass de Farimos)

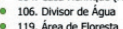

118. Area de Floresta
151. Cas de Farinha de Barro Letite

149. Ciaçaco Codorna Seu Narciso

139. Roç Ana Poula (Antiga Res. Tiadora)
152. Ro de Uussara (Antigo N. Resid. de Barro Letre)

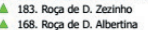

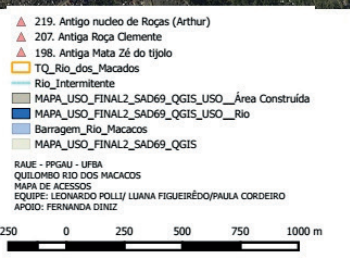

A 176. Roca D. Madalena

Do1. Roç de

$\Delta$
$\Delta$

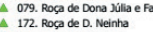

2. 237. Roç Galego
2227. Roca Edcarlos

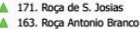

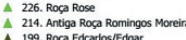

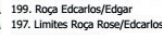

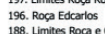

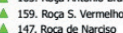

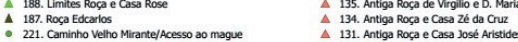

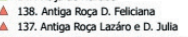

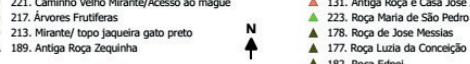

Fonte: CORDEIRO, 2014

Com a perseguição, a comunidade desenvolveu um tipo de produção que, convencionou-se a denominar de consórcios agroflorestais - prática 
ancestral já conhecida pela comunidade. Os consórcios mesclam a existência de culturas produtivas com outros tipos de vegetação. Como exemplo, hoje a plantação de cacau em área de gameleira, no Mirante da Jaqueira.

Existe no território a prática produtiva da mariscagem nos manguezais, localizados principalmente na Baía de Aratu (acesso pelo norte) e da pescaria, tanto no rio quanto no mar. A pescaria nos rios do Barroso e dos Macacos é lembrada com muita alegria pelos mais velhos, lá eles se reúnem para confraternizar. É nos rios também que as mulheres lavam roupas, bem como pegam água para cozinhar os alimentos e para uso geral da casa. A água utilizada para a irrigação é também das fontes, rios e charcos das proximidades. $\mathrm{O}$ mapeamento territorial permite afirmar que a água tem diversos usos no território, relacionados com a soberania alimentar, a geração de renda e lazer desta comunidade. Sem água, portanto, não há sustentabilidade para que a vida e a tradição quilombola da pesca artesanal e de pequena escala sejam mantidas.

A lógica de apropriação das áreas de pesca pelos quilombolas é a do valor de uso, na qual o pescador garante a sua subsistência. Ao excluir as áreas tradicionais de pesca, a regularização proposta pelo INCRA destrói a territorialidade e o modo de produzir quilombola, bem como institucionaliza a fome dentro do território.

No que se refere à produção agrícola, o mapa demonstra a espacialização do conflito fundiário. Nota-se que, no núcleo ao norte, mais distante da Vila Naval, há maior concentração de roças no território, isso porque a maior parte das roças e casas foram destruídas durante a construção da Vila Naval da Barragem e da Barragem, seguidas do impedimento de reconstrução. É necessário considerar que junto com as roças foram destruídas as casas de farinhas - como, por exemplo, as mapeadas por nós (Mapa 8): 050, 104, 151 - do território, os viveiros de aves, e apesar de todas as violências, a produção agrícola persiste no território.

O território como um todo é composto de vegetação típica da Mata Atlântica do tipo Ombrófila, vegetação com grande potencial para extrativismo de dendê, como ocorre no território. Existem alguns locais onde houve degradação do ambiente vegetal, principalmente nas margens do Rio da Saúde (54). Nessa área a vegetação foi retirada para extração de matéria-prima para a construção da Vila Militar. Outro caso de desmatamento significativo foi à construção do campo de treinamento da Marinha, local que guarda até hoje o registro desse período incômodo na memória quilombola. Esses casos de desmatamento não dão a tônica do território, já que são casos isolados e de influência externa. A comunidade de Rio dos Macacos tem utilizado a natureza local com bastante sabedoria, respeitando os princípios ambientais de produção sustentável. 
É necessário encararmos que "O território delimitado compreende a áreas onde a comunidade vive e a área necessária para a garantia mínima de sua sustentabilidade econômica, ambiental, social e cultural" (INCRA, 2012, p. 414). A redução proposta pelo INCRA fere a soberania alimentar e produtiva dessa comunidade, deixando-a vulnerável frente à expansão urbana própria do capitalismo brasileiro, marcada por "quartos de despejo". Fere também os princípios que norteiam toda a política quilombola brasileira.

\section{A AÇÃO POLÍTICA ATRAVÉS DA CARTOGRAFIA: PARA SEGUIR E NÃO APENAS CONCLUIR}

A ação política desempenhada pelo Quilombo Rio dos Macacos para a garantia de seu território tradicional e as práticas cartográficas dessa comunidade são o reflexo de dois elementos: 1) Da força organizativa que essa comunidade possui; 2) Da negação do território por parte dos agentes hegemônicos, seja do Estado ou das Forças Armadas, no caso da Marinha, negação essa fundada no racismo

Ao longo desse artigo percebe-se que enquanto a cartografia esteve confinada na mão dos especialistas e legitimada pelo império da técnica, a representação territorial desconsiderou elementos fundamentais para a definição das múltiplas territorialidades quilombolas. A análise esteve centrada em um único ponto de vista. Ponto de vista esse baseado na compreensão do território enquanto recurso, o território normado e das normas, normas estas estabelecidas pelas práticas racistas ora exercidas pela Marinha ora por agentes do Estado. É o território das verticalidades, na qual a visão exógena, estranha, define o território de outrem (SANTOS, 2006).

A publicação do RTID, definindo o território quilombola passível à regularização com apenas 104 ha fragmentados em dois núcleos, desconsidera a unidade quilombola, os espaços sagrados, de memória, de cultivo, imprimindo características que levam essa comunidade rumo a favelização (Mapa 9). Nesse sentido, as políticas de ordenamento incidentes no Quilombo Rio dos Macacos se somam a tentativa de branqueamento da população brasileira, tentativa essa que envolve "diretamente um conjunto de políticas no ordenamento territorial (nas mais diversas escalas), que possuiu como impacto o controle sobre a reprodução da vida de grupos populacionais" (CORRÊA, 2017, p.118). 
Mapa 9 - Perdas territoriais Quilombo Rio dos Macacos dos 301 hectares aos 104 hectares

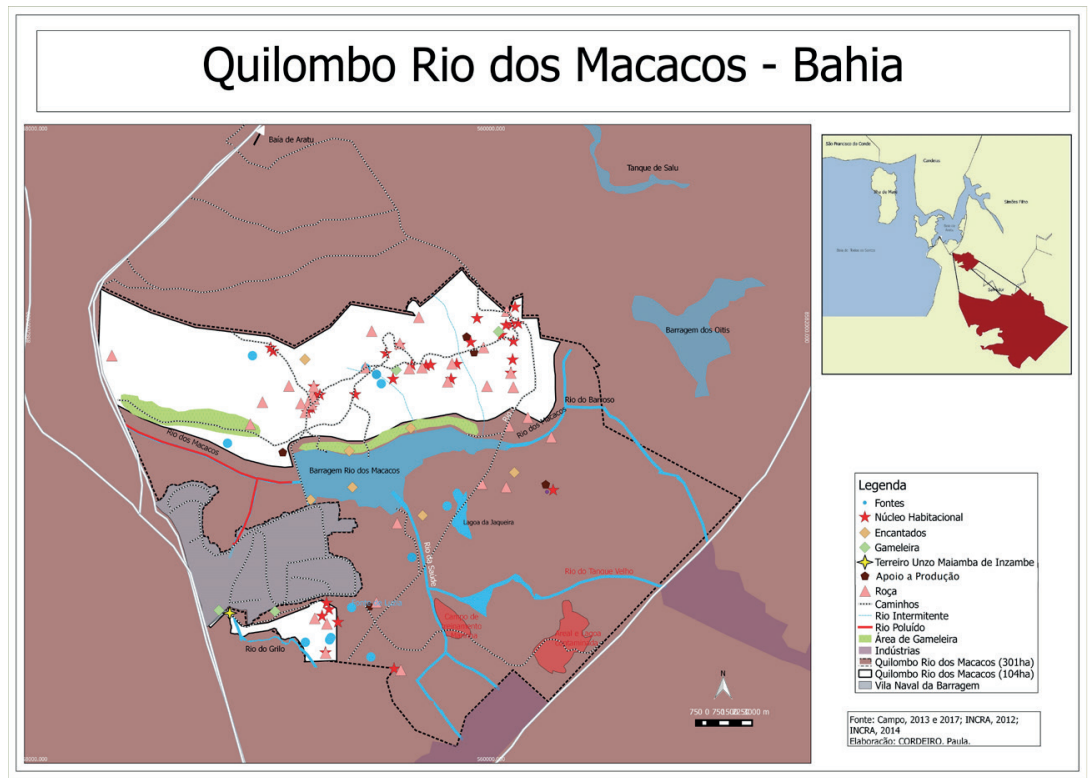

Fonte: CORDEIRO, 2018

Desde a chegada dos primeiros africanos no Brasil, que esse povo em diáspora tem seu acesso ao território negado, sendo vítima dos processos de expulsão, marginalização e de genocídio. Ao mesmo tempo, é também histórica a resistência baseada em práticas coletivas cotidianas geradoras de ação política, como diz Milton Santos:

Pode-se dizer, também, que esse cotidiano homólogo leva a um aumento da eficácia política. [...] Os mesmos interesses criam uma solidariedade ativa, manifestada em formas de expressão comum, gerando, desse modo, uma ação política (SANTOS, 2006, p. 195).

A essa ação política soma-se a possibilidade de acesso à cartografia e suas ferramentas, rompendo a barreira entre os especialistas, as populações autóctones e os territórios mapeados. Ao realizar o mapeamento o Quilombo Rio dos Macacos revive as histórias, determina os contornos de seu território e preenche a poligonal imposta verticalmente de narrativas, vidas, cores, conflitos e afetos.

A cartografia aqui, desloca-se de seu papel colonial, de conquista e de imposições para tornar-se afetiva, ao tempo que desvela um novo território em conflito não apenas nas negociações, mas também nas formas de entendimento territorial. O Quilombo Rio dos Macacos apresenta-nos o território da vida em contraposição ao território militarizado.

O conflito territorial no Quilombo Rio dos Macacos não se encerrou, nova audiência foi realizada em 2018, porém sem avanços no que concerne a regularização fundiária, aos direitos sociais e as políticas públicas. Por outro lado, fortalece-se a necessidade do uso compartilhado da barragem de Rio dos Macacos, ao ponto de que, nessa quinta audiência, realizada em fevereiro de 2018, o Comandante do $2^{\circ}$ Distrito 
Naval admitiu, de forma inédita, a possibilidade do uso compartilhado do Rio dos Macacos, porém com a restrição da construção de um muro cercando a barragem, sendo sujeitado o acesso através de portão, na qual apenas os quilombolas cadastrados pela Marinha teriam acesso.

A guerra território por modos de vida está acontecendo, o Quilombo Rio dos Macacos iniciou essa disputa com a ameaça de desapropriação e hoje possui o título fundiário de 104 hectares (2020), possuindo avanços na regularização de seu território, tendo ainda a questão da utilização da mata, das águas dos rios e da barragem do Rio dos Macacos não resolvida. Acompanhar essa história desde 2009, de diversas formas, me faz perceber o quanto a práxis cartográfica permite disputar a direção dos mundos. Respeitar os saberes e os conhecimentos quilombolas faz da cartografia um valioso aporte na afirmação dos territórios quilombolas, bem como dos demais povos e comunidades tradicionais. Por demanda da comunidade, novas cartografias virão, novas disputas territoriais e cartográficas serão travadas.

\section{NOTAS}

1. O Rio dos Macacos é um rio que banha diversas comunidades nos municípios de Salvador e Simões Filho, na década de 1970 foi barrada pela Marinha do Brasil.

2. Ofício n. 299/2012/AE/SG/PR.

3. Já havia sido proposto antes a oferta de 7,5 hectares durante a primeira audiência pública envolvendo as partes.

4. A proposta não foi apresentada oficialmente, pois Deborah Duprat suspendeu a Audiência Pública devido a ameaça sofrida pela comunidade de desapropriação.

5. Disponível em: <http://noticias.r7.com/bahia/rio-dos-macacos-mpfdefende-suspensao-de-processo-contra-quilombolas-07052014. Acesso em: 11 nov. 2020.

6. Quarto de despejo é uma expressão utilizada por Carolina Maria de Jesus em seu livro Quarto de despejo: diário de uma favelada.

\section{REFERÊNCIAS}

ACSELRAD, Henri; COLI, Luis. Disputas Territoriais e Disputas Cartográficas. In: ACSERALD, Henri (Org). Cartografias Sociais e Território. Rio de Janeiro: IPPUR/UFRJ, 2008.

ANJOS, Rafael Sanzio. Quilombos: Geografia Africana-Cartografia ÉtnicaTerritórios Tradicionais. Brasília: Mapas Editora \& Consultoria, 2009.

BRASIL. Quilombolas do Rio dos Macacos rejeitam acordo proposto pelo Governo Federal que atende grande parte de suas reivindicações. Disponível em: <http://www.secretariageral.gov.br/noticias/2014/05/09-05-2014- 
quilombolas-do-rio-dos-macacos-rejeitam-acordo-proposto-pelogoverno-federal-1>. Acesso em: 09 mai. 2014.

CASTRO, Iná Elias de. Território do Estado: Divisão ou fragmentação? Argumentos para um debate necessário. In: PERTILE. (Org.). Estado, Território e a Dinâmica das Fronteiras: Reflexões e Novos Desafios. Salvador: JM Gráfica e Editora LTDA, p. 33-52, 2013.

CORDEIRO, Paula Regina. A comunidade quilombola de Rio dos Macacos: um conflito cotidiano entre o território militarizado e o território da vida. Salvador: [s.e.], 2014. 82p.

CORDEIRO, Paula Regina. Diretrizes produtivas da Comunidade Quilombola de Rio dos Macacos. 2014. 43f. Monografia (Especialização) - Faculdade de Arquitetura e Urbanismo, Universidade Federal da Bahia, Salvador, 2014. CORDEIRO, Paula Regina. Essa terraépara filh@se net@s, não vende e não pode trocar: A disputa entre o território tradicional Quilombola-Pesqueiro de Rio dos Macacos e o território militarizado da Marinha do Brasil. 206p. Dissertação (Mestrado em Geografia) - Programa de Pós-Graduação em Geografia, Universidade Federal da Bahia, 2018.

CORDEIRO, Paula Regina; FIGUEIREDO, Luana; POLLI, Leonardo de Souza. Relatório Síntese de Caracterização da Comunidade Quilombola de Rio dos Macacos. Residência AU+E. PPGAU/UFBA, 2014.

CORREA, Gabriel Siqueira. O branqueamento do território como dispositivo colonialidade do poder: notas sobre o contexto brasileiro. In: CRUZ, Valter do Carmo. Geografia e Giro Descolonial: Experiências, ideais e horizontes de renovação do pensamento crítico. Rio de Janeiro: Letra Capital, 2017.

EMBRAPA. Variação Geográfica do Tamanho dos Módulos Fiscais no Brasil.

Disponível em: <http://ainfo.cnptia.embrapa.br/digital/bitstream/ item/77505/1/doc-146.pdf>. Acesso em: 06 nov. 2014.

GEOGRAFAR. Geografia dos Assentamentos na Área Rural. Relatório Técnico n.01/2012. Salvador, 2012.

INCRA. Instituto Nacional De Colonização E Reforma Agrária. Relatório Técnico de Identificação e Delimitação do Território da Comunidade Quilombola de Rio dos Macacos. Salvador, 2012.

SANTOS, Emerson. Disputas cartográficas e lutas sociais: Sobre representação espacial e jogo de poder. Disponível em: <http://www. ub.edu/geocrit/coloquio2012/actas/16-R-Nascimento.pdfhttp://www. ub.edu/geocrit/coloquio2012/actas/16-R-Nascimento.pdf>.2012. Acesso em: 30 fev. 2018.

SANTOS, Milton. A Natureza do Espaço: Técnica e Tempo, Razão e Emoção. 4. ed. São Paulo: Editora da Universidade de São Paulo, 2006. 